\title{
Cesarean Section Rate and Indications in Primigravida in El Shatby Hospital, Alexandria, Egypt
}

Helmy A Rady

\section{ABSTRACT}

Background: There is a significant increase in the total cesarean rate with primary cesarean accounting for most of the increase. Identifying sources of variation in cesarean use is crucial to improving the consistency and quality of obstetric care.

Aim: The aim was to asses CS rate and indications in primigravida at El Shatby maternity university hospital.

Patients and methods: the study included 952 primigravidas attending to El Shatby Hospital for delivery, assessment of the type of delivery vaginal or cesearean.

Women were divided into two groups as regards mode of delivery and indications of CS.

Results: CS rate is increasing now especially in primigravida, CS accounting $46.01 \%$ of all primigravida, fetal distress is the most common indication, abnormal presentations comes second and sever PET.

Conclusion: There is a significant increase in the total cesarean rate with primary cesarean accounting for most of the increase.

Keywords: Ceserean section, El Shatby Hospital, Primigravida.

How to cite this article: Rady HA. Cesarean Section Rate and Indications in Primigravida in El Shatby Hospital, Alexandria, Egypt. J South Asian Feder Obst Gynae 2018;10(Suppl 2):381-383.

\section{Source of support: Nil}

\section{Conflict of interest: None}

The ethics committee, faculty of medicine, Alexandria University; 0303199/2016

Date of received: 2 April 2017

Date of acceptance: 11 April 2018

Date of publication: July 2019

\section{INTRODUCTION}

Cesarean section rates, especially in primigravida, are increasing worldwide nowadays, many indications are the main cause of this like obesity, increasing maternal age especially in the first pregnancy, more multiple pregnancies

Consultant

Department of Obstetrics and Gynaecology, Faculty of Medicine, Alexandria, Egypt

Corresponding Author: Helmy A Rady, Consultant, Department of Obstetrics and Gynaecology, Faculty of Medicine, Alexandria, Egypt, e-mail: helmyabdelsatar@gmail.com and also the appearance of new indication which is a maternal request for nonmedical reasons. ${ }^{1}$

The cesarean section now becomes one of the most common surgical procedures worldwide even in developed countries. ${ }^{2}$

Womens and infants right is safe delivery naturally through the vagina; however, cesarean deliveries are increasing now. ${ }^{3}$

Till now there is a wide variation in CS rates among countries and even among hospitals, some obstetricians may perform CS to avoid vaginal delivery hazards, but CS entails more hazards. ${ }^{4}$

Delivery by CS usually associated with higher rates of pain, breastfeeding difficulties and next pregnancy complications. Even neonatal complications increase with CS like respiratory distress and ventilation. ${ }^{5}$

So assessment of benefits of CS versus complications should be assessed well before decision making. ${ }^{6}$

CS rates are increased generally, but we still find very big variations among hospitals may be due to clinical and nonclinical causes. ${ }^{7}$

One-fourth of the primary CS is reported to be performed in the second stage of the labor but are more complicated compared to the ones performed in the first stage. ${ }^{8}$

\section{AIM}

Was to asses CS rate and indications in primigravida at El Shatby maternity university hospital.

\section{PATIENTS AND METHODS}

The study included 952 primigravidas attending to El Shatby hospital for delivery, assessment of the type of delivery normal or cesarean.

Women were divided into two groups as regards the mode of delivery and indications of CS.

\section{RESULTS}

CS rate in primigravida is increasing now, in this study CS was $46.01 \%$ in comparison to $53.99 \%$ for NVD (Table 1 and Fig. 1).

Among many indications for CS fetal distress comes first, followed by an abnormal presentation and sever PET (Table 2 and Fig. 2). 


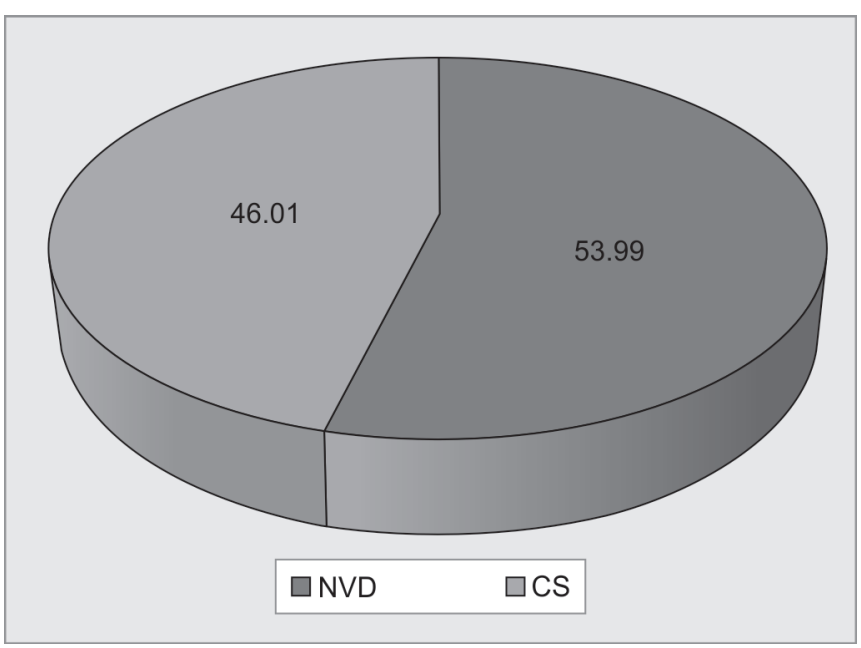

Fig.1: CS rate in primigravida

\section{DISCUSSION}

CS, especially in primigravida, is increasing now, many reasons are responsible for this increase like multiple pregnancies

In our study CS rate in primigravida was about $46.01 \%$ and fetal distress is the most common indication followed by an abnormal presentation and sever PET

In a study performed by Kozhimannil et al. ${ }^{3}$ The average hospital prevalence of cesarean section was 33.0\% among all births, and the mean prevalence of primary cesarean section was $22.0 \%$, defined among women with no prior cesarean section. The commonest indications were diabetes with pregnancy, hypertensive disorders with pregnancy, antepartum hemorrhage, fetal distress, cephalopelvic disproportion and high maternal age (more than 35 years).

In a study performed by Martin et al., ${ }^{9}$ dystocia is the most common indication for primi CS followed by a breech presentation and finally fetal distress.
Table 1: CS rate in primigravida

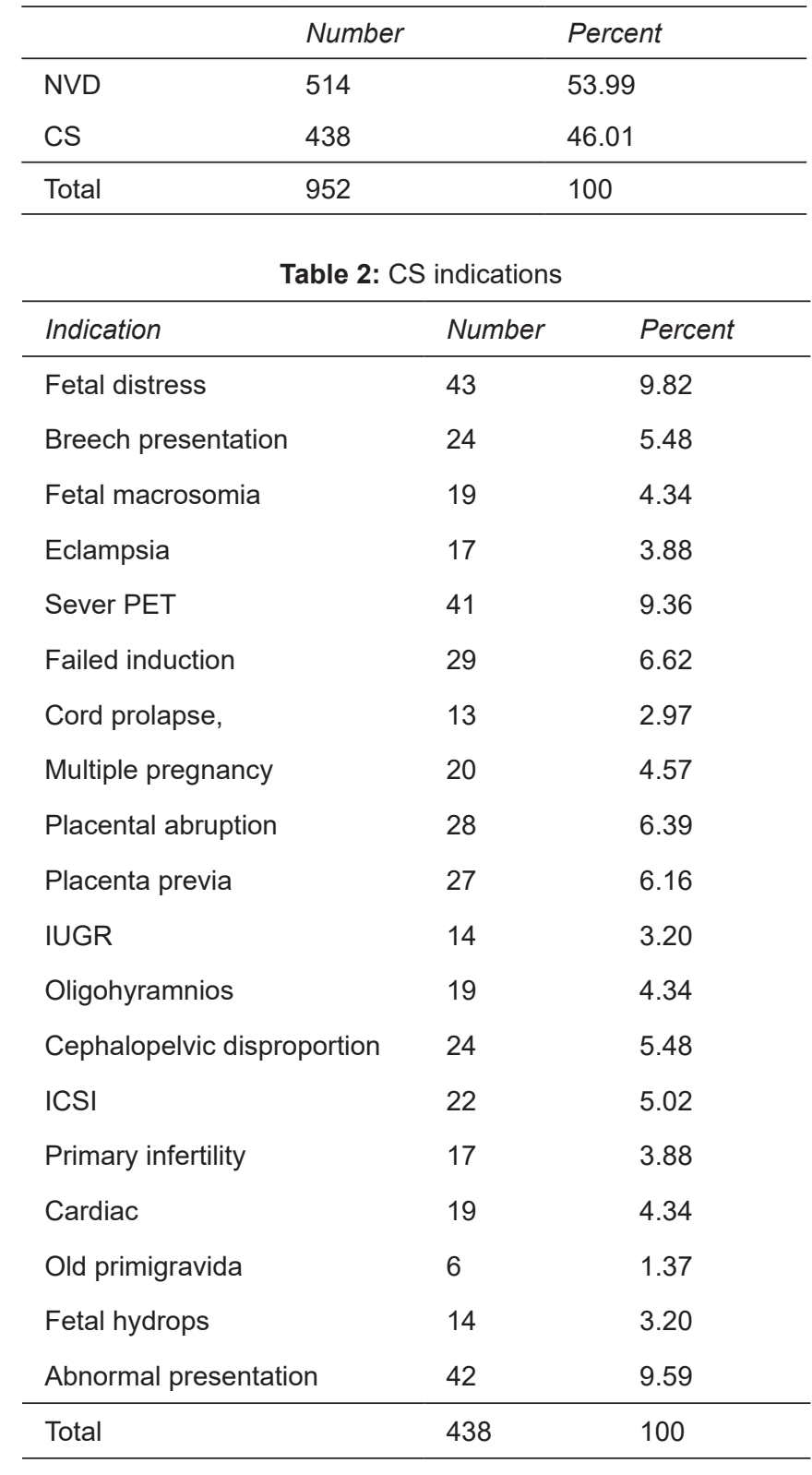

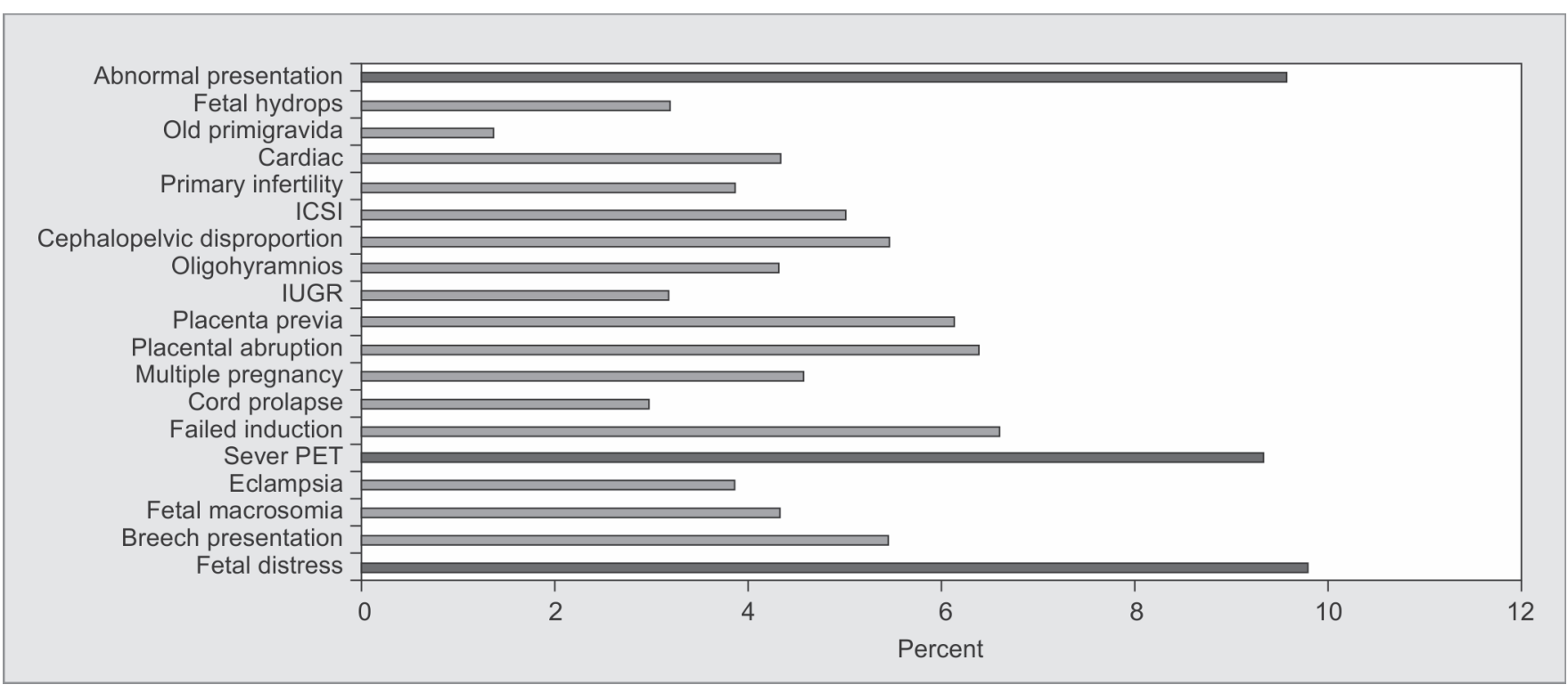

Fig. 2: CS indications 
In a study performed by Belay et al. ${ }^{8} \mathrm{CS}$ rate of $30.1 \%$ of cases. The most common indications in the first stage were non-reassuring fetal heart rate pattern (NRFHRP) accounting for $37.8 \%$ followed by arrest or protraction disorder of $23.4 \%$, whereas the commonest indication for the second stage Cs was cephalopelvic disproportion 48.5\%.

\section{Compliance with Ethical Standards}

All procedures performed in studies involving human participants were in accordance with the ethical standards of the institutional and/or national research committee and with the 1964 Helsinki declaration and its later amendments or comparable ethical standards.

\section{REFERENCES}

1. Nagy S. Changing trends and indications for cesarean section in thelast few decades. Orv Hetil 2014;155(29):1140-1146.

2. Al Rowaily MA, Alsalem FA, et al. Cesarean section in a high-parity community in Saudi Arabia: clinical indications and obstetric outcomes. BMC Pregnancy and Childbirth 2014;14(1):92.

3. Kozhimannil KB, Arcaya MC, et al. Maternal clinical diagnoses and hospital variation in the risk of cesarean delivery: analyses of a National US Hospital Discharge Database. PLoS Med 2014;11(10):e1001745.

4. Sinnott SJ, Brick A, et al. National variation in caesarean section rates: A Cross Sectional Study in Ireland. PLoS One 2016;11(6):e0156172.

5. Silver RM. Implications of the first cesarean: perinatal and future reproductive health and subsequent cesareans, placentation issues, uterine rupture risk, morbidity, and mortality. Semin Perinatol 2012;36:315-323.

6. Queenan JT. How to stop the relentless rise in cesarean deliveries. Obstet Gynecol 2011;118:199-200.

7. Lowe NK. The overuse of cesarean delivery. J Obstet Gynecol Neonat Nurs 2013;42:135-136.

8. Belay T, Yusuf L, et al. A comparative study on first stage versus second stage caesarean section on maternal and perinatal outcome. Ethiop Med J 2014;52(1):1-8

9. Martin JA, Hamilton BE, et al. Births: final data for 2006. Natl Vital Stat 2009;58(24):1-85. 